\title{
The role of NGOs in negotiating the use of biodiversity in marine areas beyond national jurisdiction
}

\author{
Robert Blasiak $^{\mathrm{a}, \mathrm{b}, *}$, Carole Durussel $^{\mathrm{c}}$, Jeremy Pittman ${ }^{\mathrm{d}}$, Carole-Anne Sénit ${ }^{\mathrm{e}}$, Matilda Petersson ${ }^{\mathrm{f}}$, \\ Nobuyuki Yagi ${ }^{\mathrm{a}}$
}

a Graduate School of Agricultural and Life Sciences, The University of Tokyo, 1-1-1 Yayoi, Bunkyo-ku, Tokyo, Japan

b United Nations University Institute for the Advanced Study of Sustainability, 5-53-70 Jingumae, Shibuya-ku, Tokyo, Japan

c Institute for Advanced Sustainability Studies, Berliner Strasse 130, 14467 Potsdam, Germany

d School of Environment, Resources and Sustainability, University of Waterloo, 200 University Ave W, Waterloo, ON, Canada N2L 3G1

e Copernicus Institute of Sustainable Development, Utrecht University, Domplein 29, 3512 Utrecht, The Netherlands

f Stockholm Resilience Centre, Stockholm University, Universitetsvägen 10, 11418 Stockholm, Sweden

\section{A R T I C L E I N F O}

\section{Keywords:}

Stakeholder engagement

International negotiations

BBNJ

Biological diversity

Marine biodiversity

Consensus building

\begin{abstract}
A B S T R A C T
In 2004, the UN General Assembly resolved to establish a working group to consider issues pertaining to the conservation and sustainable use of marine biodiversity in areas beyond national jurisdiction (BBNJ). The group met nine times between 2006 and 2015 before concluding its mandate by recommending the development of an international legally binding instrument on BBNJ under the United Nations Convention on the Law of the Sea. Based on in-depth interviews with working group participants, this research examines how NGOs contributed to the working group process. Respondents from government delegations highlighted the usefulness of workshops and side events convened by NGOs, and the role of NGOs in bringing experts on technical issues - particularly marine genetic resources and the sharing of benefits - into the BBNJ negotiations. Respondents from both NGOs and government delegations emphasized the importance of fostering personal relationships in order to ensure a steady and constructive information flow. Social media efforts by NGOs were considered by some government representatives to have occasionally hampered open discussion, although they noted that conditions have improved. The lengthy working group process was marked by substantial fluctuation in participation, particularly within government delegations from developing states. Of 1523 individuals who participated in at least one of the working group meetings, only 45 attended more than half of the meetings, and $80 \%$ of these were representing NGOs or highly industrialized countries. Respondents felt that this comparatively small number of individuals provided a source of continuity that was crucial for moving the discussions forward.
\end{abstract}

\section{Introduction}

Non-governmental organizations (NGOs) have become a ubiquitous presence in policy-making and action from the local to the international level on issues as diverse as promoting human rights, banning land mines and fostering nature conservation. The origin of the term itself can be traced back to the formation of the United Nations, and its founding charter, which specifies that "the Economic and Social Council may take suitable arrangements for consultation with nongovernmental organizations" [33]. While the definition of what constitutes an NGO differs depending on context and setting, in its most fundamental sense, an NGO must be free of direct government control [37].

Pinpointing when environmental NGOs became significant players within the international community is challenging, but some have pointed to the run-up to the United Nations Conference on the Human Environment, held in Stockholm, Sweden in 1972 [11,3]. An informal group of NGOs, experts and policy-makers joined together in mid-1971 to draft what became known as the Founex Report on Environment and Development, which subsequently contributed to the framing of the conference and its outcomes, and to this meeting now being considered the first instance of regional cooperation on environmental issues $[27,11]$. The intervening years have seen a huge growth not only in the number of NGOs participating and having access to international negotiations and policy processes $[4,25]$ but that also have the capacities to contribute to the steering of such political processes [5]. The number of NGOs that have successfully obtained consultative status with the United Nations Economic and Social Council (ECOSOC), for instance, has increased by more than $500 \%$ over the past 30 years (from 712 in 1984 to 4045 in 2014) [37].

\footnotetext{
* Corresponding author at: Graduate School of Agricultural and Life Sciences, The University of Tokyo, 1-1-1 Yayoi, Bunkyo-ku, Tokyo, Japan.
} 
NGOs are active in a multitude of policy landscapes, and employ a diverse range of strategies to contribute to international processes, albeit with varying levels of success. For instance, a crucial role has been attributed to NGOs in building political consensus enabling an international ban on the use of land mines [28] and a global framework for forest management and the trading of timber [19], but decades of NGO efforts to reshape the World Bank's approach to development were considered unsuccessful [26]. The multitude of strategies used by NGOs to contribute to international policy processes includes directly participating in international forums and meetings, providing information and expertise, advocating their views through coalitions or direct and indirect lobbying as well as using the media to mobilize public opinion $[15,21,32]$. All of these strategies have the potential to contribute to the direction and content of international negotiations, and great scholarly interest therefore exists in identifying how and when such strategies are successful $[31,8,32]$. In recent years, NGOs have been heavily involved in shaping the global development agenda, perhaps most notably in the context of the Sustainable Development Goals (SDGs) [20]. Nevertheless, conceptualizing NGO influence, or drawing one-to-one correlations between NGO actions and negotiation outcomes, remains notoriously difficult [10].

This paper explores perceptions of how NGOs are contributing to the outcomes of the working group mandated by the United Nations General Assembly (UNGA) to look into issues related to the conservation and sustainable use of biodiversity in marine areas beyond national jurisdiction (BBNJ Working Group). After detailing the history and context of the BBNJ negotiations, a two-part methodology is introduced, which draws on a set of semi-structured interviews with individuals who participated in the BBNJ Working Group as representatives of governments or NGOs, and an assessment of participant lists from the nine meetings of the BBNJ Working Group between 2006 and 2015. Only NGOs with consultative status approved by ECOSOC were eligible to independently register their participation in the BBNJ Working Group, so use of the term "NGOs" throughout the remainder of this paper specifically refers to such organizations with at least one representative attending at least one of the BBNJ Working Group meetings. ${ }^{1}$

\section{Biodiversity beyond areas of national jurisdiction (BBNJ)}

\subsection{Identifying gaps in the legal framework for managing marine areas beyond national jurisdiction}

A crucial element within the United Nations Convention on the Law of the Sea (UNCLOS) of 1982 was the formalization of maritime zones for the seabed and water column. Under UNCLOS, the seabed beyond national jurisdiction is known as 'the Area'. Exclusive economic zones (EEZs) form a 200-nautical mile swath extending from coastlines, within which each respective country has sovereign rights and obligations, including on the management and use of natural resources. Marine areas beyond national jurisdiction (ABNJ) cover nearly half the world's surface. The biodiversity in areas beyond national jurisdiction (BBNJ) remains comparatively unknown, but concerns are growing over the conservation and sustainable use of BBNJ due to a rapidly expanding array of human activities in ABNJ over recent decades [23]. Such activities notably include fishing, shipping, the laying of submarine cables, exploration of mineral resources, and marine scientific research [6]. Moreover, each of these activities is managed and regulated to varying degrees by different sectoral bodies (see Ardron et al. [2] for a comprehensive overview of these organizations and their areas of responsibility).

\footnotetext{
${ }^{1}$ A list of the 4189 NGOs that have consultative status with the Economic and Social Council (ECOSOC) as of 1 September 2014 can be accessed here: http://csonet.org/ content/documents/E-2014-INF-5\%20Issued.pdf (retrieved 28 December 2016)
}

Subsequently, a range of legal, institutional and regulatory gaps in the governance of ABNJ, and consequently BBNJ, have been identified, including a lack of overarching governance principles; the absence of a global framework for the establishment or management of marine protected areas in $\mathrm{ABNJ}$; uncertain legal status of marine genetic resources collected in ABNJ; no globally accepted rules on the application of environmental impact assessments and strategic environmental assessments (Wright et al., 2016). Moreover, management of ABNJ has been characterized by a lack of collaboration and cooperation among international, regional and sectoral organizations.

\subsection{Formation and Mandate of BBNJ Working Group}

The complexity of the governance landscape in ABNJ with its high level of sectoralization and fractionalization makes action or changes to the status quo challenging. Consequently, the growing interest in BBNJ led to the issue ultimately being picked up by the United Nations General Assembly (UNGA). Wright et al. [38,39] highlight two factors that have led to the UNGA being deemed the only political arena that could appropriately handle the issue as a whole: firstly, its universality (193 members), and secondly the tendency for issues related to the Law of the Sea being discussed under the UNGA.

In November 2004, with UNGA Resolution 59/24, the "Ad Hoc Open-Ended Informal Working Group to study issues relating to the conservation and sustainable use of marine biological diversity beyond areas of national jurisdiction" (hereafter, BBNJ Working Group) was established with a four-fold mandate: (1) to survey past and present activities related to BBNJ; (2) to examine the issue from a range of scientific, technical, legal and other perspectives; (3) to identify key issues and questions where further study is needed; (4) to indicate potential options and approaches to move forward with the conservation and sustainable use of BBNJ (UNGA 2004).

\subsection{Key stages in the BBNJ negotiation process}

The BBNJ Working Group met nine times, starting in 2006 and ending in 2015, with the conclusion of its mandate. Overall, the process was characterized by three relatively distinct stages (for more detailed perspectives on the individual meetings, see Morgera [24] and Wright et al. $[38,39])$.

During the first stage, with BBNJ Working Group meetings held in 2006, 2008 and 2010, the scope and content of the discussions began to take form, and clear divisions between state groups grew apparent. In particular, states diverged almost immediately on the legal status of marine genetic resources (MGRs) collected in ABNJ. One interpretation holds that MGRs collected in the seabed fall under the common heritage of mankind principle that governs the exploitation of seabed mineral resources in UNCLOS Part XI [34], while a second interpretation of the same UNCLOS text holds that MGRs are not defined in UNCLOS and therefore should be handled under the principle of freedom of the high seas [12]. Other delegations raised issues such as the need for a legal framework and institutional mechanism to establish marine protected areas (MPAs) in ABNJ, and pathways to enshrining the precautionary approach in the management and use of BBNJ [38,39].

The second stage of the BBNJ Working Group began with its fourth meeting (2011), during which the negotiations began to grow more clearly defined with key pieces of text. The 2011 meeting was characterized by extensive discussion on the need for a separate multilateral agreement on BBNJ under the auspices of UNCLOS $[38,39]$. Agreement was reached on a set of four issues, which were subsequently referred to as "the package", and which were to be the focus of future negotiations on BBNJ. As specified in a letter from the co-chairs of the BBNJ Working Group to the UNGA, the package elements were specified as "marine genetic resources, including questions on the sharing of benefits, measures such as area-based management tools, including marine protected areas, and environmental 
impact assessments, capacity-building and the transfer of marine technology" [36]. Importantly, the BBNJ Working Group recommended that these issues be considered "together and as a whole", phrasing that promotes a spirit of compromise, and places a burden on delegations to address all issues rather than tabling the most challenging [9].

Less than a year after the package issues were defined, the United Nations Conference on Sustainable Development took place in Rio de Janeiro, Brazil, marking twenty years since the landmark 1992 Earth Summit, and hence given the shortened name Rio +20 . Twenty-three paragraphs of the outcome document from Rio +20 , "The Future We Want", were dedicated to issues surrounding the oceans and seas. Paragraph 162 specifically takes up the issue of BBNJ, and signatories committed "to address, on an urgent basis the issue of the conservation and sustainable use of [BBNJ], including by taking a decision on the development of an international instrument under [UNCLOS]" before the end of the 69th UNGA session (UNGA 2012). Consequently, signatories had committed to an end goal of September 2015 for the conclusion of the BBNJ Working Group's activities.

The third stage of the BBNJ Working Group picked up on these two crucial developments: the definition of the package and a timeframe. The negotiations throughout the final meetings (2012, 2013, two in 2014, and 2015) were characterized by growing consensus, particularly around three issues: sticking to the Rio +20 deadline; the appropriateness of UNCLOS as the overarching framework for any subsequent agreement; and adherence to the package elements agreed in 2011 $[38,39]$. The BBNJ Working Group concluded its mandate at its final meeting in January 2015 with a recommendation to the UNGA to "develop an international legally-binding instrument under the Convention on the conservation and sustainable use of [BBNJ]" based on the four elements of the package agreed in 2011 [35]. Following this recommendation and before holding an intergovernmental conference, a Preparatory Committee (PrepCom) met twice in 2016 and will meet two more times in 2017 before providing substantive recommendations to the UNGA by the end of 2017 on the elements of a draft text of an international legally binding instrument. Although the BBNJ negotiations span a variety of different processes, it is important to emphasize that this research is focused on the first of these processes, namely the BBNJ Working Group (2006-2015).

\section{Methodology}

\subsection{Semi-structured interviews with BBNJ Working Group participants}

\subsubsection{Selecting interview partners}

To gather firsthand accounts and reflections on the BBNJ Working Group process, interviews were conducted with 19 individuals, who attended meetings of the BBNJ Working Group as members of government delegations, representatives of NGOs, or academic experts. The availability of interview participants varied considerably for two primary reasons. First, the contact information of most academics and NGO representatives was available on public websites, while the opposite was true for government delegation members. Second, most interviews were conducted during the second meeting of the BBNJ Preparatory Committee (BBNJ PrepCom 2: 26 August - 9 September 2016), and as demonstrated by the analysis of BBNJ Working Group participation, there is a considerably higher continuity in the representation of NGOs than most government delegations (see Section 4.2). Prior to the start of BBNJ PrepCom 2, it was therefore possible to establish contact with representatives of most NGOs who attended the BBNJ Working Group (but not government representatives), and inquire about the possibility of scheduling an interview.

Interviews with representatives of government delegations were primarily arranged and carried out after BBNJ PrepCom 2 concluded. Recognizing the severe challenges of collecting a comprehensive or fully representative set of interview partners from among the many government delegations, we approached governments based on three criteria: (1) active engagement in the negotiations (based, subjectively, on the impressions of the two lead authors of this article from attending previous BBNJ meetings, and the daily meeting reports provided by the IISD $^{2}$ ); (2) regional representation (at least two governments from each of the UN's five regional groups ${ }^{3}$ ); (3) individual continuity within the delegation (at least one member of the country's delegation participated in the three most recent BBNJ Working Group meetings and BBNJ PrepCom 1).

In line with the principles of transparency and informed consent, all respondents were first provided with a written description of the aims of the research, how the information collected in the interviews would be used, and the expected outputs [17]. Specifically, it was emphasized that the interviews would only focus on the BBNJ Working Group, which concluded its mandate in 2015, and how and to which extent NGOs contributed to this process. Furthermore, the lead researchers explained their perception that the BBNJ Working Group generated two main outcomes, namely the formulation of the four "package" elements, and the building of consensus on the need to move forward with negotiations on an international legally binding instrument on the conservation and sustainable use of BBNJ. Respondents were moreover informed that all interviews would be confidential, and viewpoints expressed would not be attributed to any individuals, countries or organizations in future publications, specifically an article in a peerreviewed academic journal on the contribution of NGOs to the BBNJ process.

It should be noted that the BBNJ Working Group also included participants from intergovernmental organizations and UN agencies, as well as the UNDOALOS secretariat staff. These participants were in a somewhat delicate position, as they could not negotiate positions on behalf of their member states or signatories, namely the governments represented by delegations in the BBNJ Working Group. These organizations and agencies did, however, contribute to the negotiations by providing clarifications and explanations about their activities relevant to BBNJ. Participants representing international governmental organizations, UN agencies and UNDOALOS were therefore not interviewed for this research, but their perceptions of the contribution of NGOs to the BBNJ Working Group process would be an interesting topic for future study.

\subsubsection{Conducting the interviews}

Interviews were conducted with individual respondents. Along with granting anonymity to all respondents, this individualized approach was meant to elicit more forthcoming answers and facilitate a more open dialogue. Prior to conducting the interviews, the two lead authors of this study discussed and agreed on a set of questions to provide structure to the interviews as well as common reference points for subsequently assessing them. Slightly different sets of questions were developed for NGO representatives, representatives of academia, and government delegation members. Questions on the respective lists included, e.g. "How and when did you become involved with BBNJ issues?"; "How, if at all, did the contribution of your [organization/ NGO] change over the course of the BBNJ negotiations?"; "What tools/ resources did your delegation use to gather information about the BBNJ process over the course of the negotiations?" (See Supplementary materials for lists of guiding questions) Although these questions formed the backbone of all the interviews, respondents were encouraged to speak freely, and the two members of the interview team posed follow-up questions or requested further clarification as needed.

The majority of the interviews were conducted jointly by a team

\footnotetext{
${ }^{2}$ The International Institute for Sustainable Development (IISD) is regularly commissioned to support environmental negotiations through reporting in print and online versions of its Earth Negotiations Bulletin (ENB), which is made available on a daily basis.

${ }^{3}$ The five regional groups of the United Nations are the African Group, Asia-Pacific Group, Eastern European Group, Latin American and Caribbean Group, and Western European and Others Group.
} 
comprised of the two lead authors of this study. Audio recordings were made, and one of the team members kept written notes during these interviews. This joint approach was found to be beneficial in two regards: 1) if one member of the team neglected to ask a key question or follow up, the other team member could fill this gap; 2) it enabled the two members of the interview team to align their interviewing styles. This second factor was particularly crucial for interviews conducted in an extended second round after BBNJ PrepCom 2 (from SeptemberNovember 2016). Due to the different time zones of the two lead authors and their interview subjects, several of the interviews in this extended second round were conducted by just one member of the twomember interview team. These interviews were based on the same set of guiding questions, and the same semi-structured questioning style employed for the interviews on the sidelines of BBNJ PrepCom 2. In one case, it was impossible to arrange an oral interview, and a respondent provided detailed written responses to the set of guiding questions used for the interviews.

\subsubsection{Assessment of interviews}

A multi-step process was used to assess the interviews conducted for this research. For each interview, a detailed summary was prepared in bullet form of key points raised by the respondent. The semi-structured nature of the interviews resulted in a very broad range of topics. With the aim of condensing this diversity of themes and opinions into a concise set of overarching topics, the K-J method, created by Jiro Kawakita to organize large groups of opinions and data into broader categories, was used to create affinity diagrams [30]. Accordingly, the bullet points from the interview summaries were first assembled into category clusters. This clustering process helped to identify themes of tangential or anecdotal relevance to the stated research questions, and these bullet points were set aside. Multiple iterations of the clustering and discarding process resulted in a set of five overarching themes. Many of the clusters corresponded with the guiding questions developed for each group of respondents (see Supplementary materials), while others, such as the role of social media in pushing or hindering progress, and mismatches in scientific and legal expertise resulted from this process.

\subsection{Assessment of participant lists}

The Secretariat of the United Nations Office of Legal Affairs; Division for Ocean Affairs and the Law of the Sea (UNDOALOS) compiled lists of participants for all nine meetings of the BBNJ Working Group. These lists of participants were collected and assessed by coding each individual participant according to their affiliation (name of NGO or government agency) and number of meetings attended. To deepen the analysis, sub-codes were created for small island developing states (SIDS), least developed countries (LDCs), members of the Group of 77 and China (G77 + China), and members of the Organization for Economic Cooperation and Development (OECD). While participation in the BBNJ Working Group does not necessarily indicate active or passive contributions to the process, it is considered here as a factor that enables such contributions to take place [10]. Moreover, this assessment enables a comparison of overall participation over the course of the BBNJ Working Group process as well as the continuity of participation by individual countries, groups of countries and NGOs. Continuous rather than sporadic participation across an entire policy process has been suggested to give NGOs a greater capacity to contribute to a process, as it provides the opportunity to directly follow the process and build up a personal relationships with key policymakers [16].

\section{Results and discussion}

Some distinct differences exist among NGOs and governments with regard to the contribution of NGOs to the BBNJ Working Group process.
Even prior to conducting the interviews, a review of previous literature pointed to three observations: (1) it would be challenging to track how the specific efforts of NGOs have contributed to this process [10,31]; (2) NGOs would likely tend to see their role in a favorable and constructive light [1]; (3) governments would be unlikely to attribute the shaping of official positions to non-governmental actors $[1,29]$.

As expected, none of the government delegation respondents felt that NGOs had contributed substantially to the definition of the four Package Deal issues. While several government delegation members spoke in very positive terms about the contribution of NGOs to the BBNJ Working Group process, the distance between the perceptions of government delegations and NGOs on this point was sometimes vast:

"NGOs have been remarkably well-engaged and influential right from the [beginning...] all the way through the working group process. It's been a remarkably positive engagement. We've been welcomed by governments who have been talking about this. The conversations have been fairly open. We've had really good access." (NGO representative 5)

"Not all civil society contributions were "expert" ones. We incorporated real experts' contributions into our considerations in order to better position ourselves. Did they change our basic position? No." (Government delegation member 4)

Nevertheless, some points of convergence were also evident, most notably on the crucial importance of personal relations between individuals representing NGOs and those on government delegations for ensuring flow of information and ideas, and the constructive role NGOs played as mediators in connecting government delegations with legal and technical experts. Findings from these interviews are divided into five major areas in the following.

\subsection{Providing scientific and legal expertise}

The package of issues defined in 2011 covered a broad range of topics that required very different types of expertise in order for delegations to engage in substantive negotiations. As one government official noted:

"In the beginning, [the BBNJ working group meetings] were confusing, having so many issues at stake. Although it was rather impossible to separate the two distinct maritime areas involved, the [General Assembly] decision to tackle such a broad issue, namely all marine biodiversity and both maritime areas (the high seas and the Area) made it a huge issue and a very difficult one to address." (Government delegation member 4)

Moreover, very few governments or NGOs were fully prepared to discuss this diverse range of issues, not only due to a lack of scientific expertise, but also legal expertise.

"One factor that contributed to lack of understanding is that even developed countries' delegations did not involve real experts, not only on [marine genetic resources] and the other types of biological organisms at stake, but also real law of the sea experts." (Government delegation member 2)

Another respondent emphasized that such deficits were also evident among highly industrialized countries, where the negotiators of UNCLOS, who had been generalists, had since been replaced by specialists, who could only speak with authority on individual issues. Initially, some governments also viewed the BBNJ process as primarily an environmental issue, and their delegations were led by environment ministry officials, resulting in what one respondent referred to as "confusion [regarding] how to tackle this issue in the context of the law of the sea." In other cases, delegations were primarily composed of permanent mission staff, with broad portfolios and limited familiarity with different aspects of the conservation and sustainable use of marine resources. 
By far the greatest deficits in scientific and legal expertise for both governments and NGOs were in relation to the first package issue, namely "marine genetic resources [MGRs], including questions on the sharing of benefits" [36 p. 2]. Overall, NGOs made the decision to focus their efforts on issues with which they had the greatest expertise (particularly marine protected areas (MPAs) and environmental impact assessments (EIAs)) rather than developing in-house expertise with regard to MGRs.

"Not all of the NGOs are able to engage on MGRs, because it's not really within their competence, [...] because they're environmental conservation organizations, so they don't have anything to say really on the equitable sharing of benefits. Just because you can't be an expert in everything." (NGO representative 3)

The emphasis of NGOs on these two package elements led several of the respondents from state delegations to feel that NGOs had a tendency to focus on the conservation of BBNJ, while paying less attention to aspects of sustainable use.

Respondents from NGOs and government delegations agreed on the importance of injecting expert knowledge about MGRs into the BBNJ Working Group process. Both groups felt that side events organized by NGOs on MGRs were a useful mechanism for inviting MGR experts from universities and the private sector to provide technical and legal expertise. Some states were able to draw on domestic expertise in preparing their positions, or even included such experts in their delegations. One MGRs expert, who was interviewed for this research, had connections with multiple NGOs and government delegations, and had spoken at multiple side events and intersessional workshops organized by NGOs. This resulted in subsequently being contacted by government delegations to provide additional advisory support. Noting a very low level of awareness surrounding the issue, the same expert also proactively reached out to governments to disseminate literature and further information on MGRs. In a further reflection of the wide range of expertise needed for the BBNJ process, the MGRs expert noted a personal lack of knowledge with regard to policy processes, and sought additional advisory support in order to develop presentations on MGRs that contained pragmatic options for informed policy-making.

Some governments also took a proactive approach to building the capacity for engaging in negotiations regarding MGRs and benefit sharing. Two government delegation members explained how they had reached out to other delegations with the specific aim of explaining the facets of MGRs and monetary and non-monetary benefit sharing. Another government delegation member emphasized that state positions were sometimes based on a lack of expertise, or unfamiliarity with the ecological or technical issues being discussed. The delegation member noted that scientists enjoyed a high level of trust among government delegations, so in such cases, NGOs and scientists have the capacity to impact the negotiations by simply providing clear explanations of the issues being negotiated.

\subsection{Providing continuity throughout the negotiations}

"We definitely have suffered from rotating of senior bureaucrats and senior foreign affairs officials. It's a bumpy road, but that's normal life." (NGO representative 3)

Compared with some UN processes, the BBNJ negotiations have extended over a very long period. The first Conference on the Law of the Sea, for instance, which resulted in four separate conventions that form the backbone of UNCLOS, extended from 1956 to 1958. Likewise, the United Nations Conference on Straddling Fish Stocks and Highly Migratory Fish Stocks, which resulted in the UN Fish Stocks Agreement, lasted from 1993 to 1995. The BBNJ Working Group alone lasted from 2006 to 2015, and even today there is no certainty that an intergovernmental conference to negotiate an international legally binding instrument on BBNJ under UNCLOS will be convened.

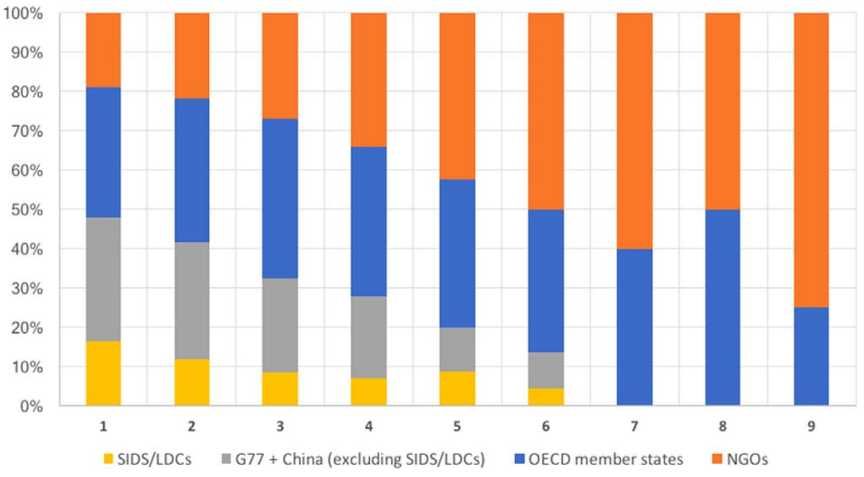

Fig. 1. Combined number of government delegates and NGO representatives who attended one or more meetings of the BBNJ Working Group.

Considering the length of the process, continuity within delegations is crucial for safeguarding expertise and ensuring continuous progress within the negotiations rather than a rehashing of previous discussions [7]. Based on an analysis of meeting participation lists, it is apparent that there was tremendous turnover in individual participation across meetings. A total of 1523 individuals joined at least one of the working group meetings, but only 45 individuals attended more than half of the meetings; 36 of these individuals were representing NGOs or highly industrialized member states of the Organization for Economic Cooperation and Development (OECD) (Fig. 1). Just four individuals attended all nine BBNJ Working Group meetings, and there was a particularly low level of continuity among small island developing states (SIDS), least developed countries (LDCs) and members of the Group of 77 and China (G77+ China). No individual from any of the 134 member states of the G77 attended more than six of the BBNJ Working Group meetings. This high rate of turnover suggests a struggle to ensure continuity of expertise and familiarity with the previous steps in the negotiation process. It likewise suggests an imbalance in the capacity of all governments to consistently contribute to the BBNJ Working Group process over time (Fig. 2).

"[Providing a unified source of information has] been absolutely crucial [...] in providing opportunities for delegates, and particularly new delegates, to get information and to get familiarized with the issues, because there's a huge turnover of delegates, and particularly for the developing world." (NGO representative 5)

NGOs have been able to help bridge gaps in the continuity of

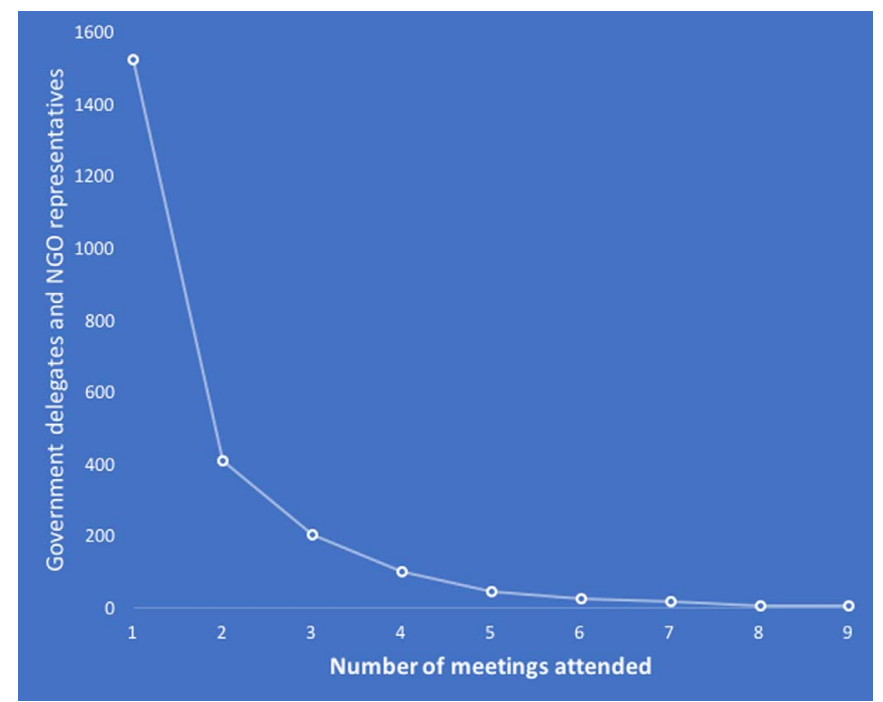

Fig. 2. Variation in continuity of individual participation in the BBNJ Working Group meetings. 
delegation expertise by providing publications that describe the history of the BBNJ process as well as the facets of each of the package issues (e.g. $[13,18])$. Intersessional workshops and side events organized by NGOs and intergovernmental organizations were also a useful tool for helping these new government delegation members assume their responsibilities and become familiarized with the BBNJ package issues.

"[...] workshops were useful both in providing a way for delegates to meet together, and discuss ideas and form a common framework, as well as to give them some of the information and tools they needed." (NGO representative 3)

\subsection{Importance of personal relations}

"As always with these things, the drivers are a relatively few number of champion delegates." (NGO representative 1)

"In my view, being on a delegation is a very good thing to do, because it gives you more access, but only to one government." (NGO representative 5)

Representatives of government delegations and NGOs were also in agreement on the importance of personal relations for ensuring a constructive flow of information. Multiple respondents emphasized that such relations take time to form, and they are often informal relationships rather than institutional or official relations, i.e. they form between individuals rather than, for instance, between a certain government delegation and a certain NGO. Such individuals were considered to be crucial connectors, such that retirements or reassignments could lead to a severed link and the need to start over with establishing connections. In early stages of the working group process, as NGOs sought to establish effective collaboration with states, a focus was placed on first contacting what respondents referred to as "sympathetic" states or "champions" for intersessional meetings and workshops. The chairs of the working group were specifically praised by some for giving NGOs the opportunity to speak in plenary, and over time awareness grew among states about the expertise available from participating NGOs, leading one government delegation member to mention in this regard that now "states know who to contact for questions or help".

Recent research on the influence of non-state actors on the definition of the Sustainable Development Goals (SDGs) has similarly demonstrated that the human factor is extremely important in intergovernmental negotiations. As influence depends on trust, most participants in the SDG negotiations, both state and non-state, concurred on the fact that NGO contributions are more likely to impact the outcomes of negotiations when their representatives have the capacity to repeatedly attend the negotiations and build as many personal relationships as possible with both members of delegations and the co-chairs of the negotiations. Increasing interaction and trust between NGO and government representatives by building such relationships is all the more important, because within the context of intergovernmental negotiations, much of the work is done outside of the negotiating room, a point emphasized by multiple participants in the BBNJ Working Group. Research on the negotiations of the Open Working Group on the SDGs, for instance, suggested that 'around $80 \%$ of meetings and consultations took place in between sessions.' ([22]: 75).

\subsection{Coalition formation}

"In setting up the High Seas Alliance, we have been able to pool our efforts quite successfully to reach out to delegates, reach out to countries." (NGO representative 1)

As in other international negotiations, coalition formation has promoted efficiency and shared messaging among NGOs during the BBNJ Working Group process $[14,21]$. Non-governmental participation in the BBNJ Working Group is restricted to some extent by the need for participating organizations to have successfully registered with ECOSOC. Several respondents also pointed out that participation is further limited by the nature of the negotiations, which require a high level of legal and scientific expertise. Moreover, several respondents pointed out that in the early stages of the BBNJ Working Group process, NGOs had a very weak voice, and in some cases delegations showed little interest in comments made by NGOs. The voice of NGOs gradually grew over the course of the BBNJ Working Group process, and a crucial development noted by some was the formation of the High Seas Alliance in 2011.

"[The] High Seas Alliance has been crucial as a coalition, because it allows people to pool resources, to exchange ideas, [which enables] us to present a very unified front, which also becomes a unified source of information for delegates. And that's been absolutely crucial [...] in providing opportunities for delegates, and particularly new delegates, to get information and to get familiarized with the issues [...]" (NGO representative 3)

Since its formation in 2011, the High Seas Alliance has grown into a coalition with a paying membership of 32 NGOs and the International Union for Conservation of Nature (IUCN), an intergovernmental organization. The aim of the High Seas Alliance has been to align and coordinate the work of NGOs on BBNJ issues to achieve a greater and more concerted impact on the negotiations. Respondents noted a number of benefits to the coalition, most notably as a platform for raising the visibility of issues promoted by the individual members, some of the smaller of which lack the resources to participate in the many relevant BBNJ meetings. Further added value was recognized in the combined regional and linguistic expertise of the individual members, making it possible in many cases to communicate with delegations in their native language. Likewise, although the High Seas Alliance has a thematic focus on the package issues of area-based management tools and environmental impact assessments, it also counts among its membership organizations that can speak to capacity building and the transfer of marine technology, and marine genetic resources, giving the Alliance a basis to make statements on all aspects of the BBNJ negotiations.

\subsection{Uncertain usefulness of social media activities}

Some divergence was evident among respondents with regard to the role of NGOs in placing pressure on governments to act, most notably through social media channels such as Twitter and blogs. More than one NGO respondent emphasized that it was the role of NGOs to make sure governments know that "they are being watched". Yet several government officials interviewed for this research also noted that such instincts can prove counterproductive if not carefully pursued.

"Actually, [although the BBNJ negotiations are] a highly political issue, [the NGOs] behaved like in environmental fora exercising many times an undue pressure on delegations. [...] They showed the tendency of qualifying some delegations as not friendly to conservation enough if they made the point that sustainable use and benefit sharing was part of the package. [...] In general, many NGO publications were accusatory or lacked completeness in the grasp of the issue." (Government delegation member 4)

In order for negotiations to move forward, governments need to feel that there is space for frank and open discussions without fear of being quoted out of context. While the instinct of NGOs may be to exert pressure to act, and to foster a state of greater transparency, a careful balance must be struck. In the case of transparency, for instance, if governments are cautious about engaging in frank discussions in a plenary setting, the likelihood of substantive discussions only taking place in closed sessions increases. While NGOs and the official rapporteurs of the Earth Negotiations Bulletin (ENB) published by the International Institute for Sustainable Development (IISD) can attend 
and freely report on open sessions, a greater tendency towards closed meetings would result in fewer opportunities for NGOs to contribute to negotiations as well as a diminished public record of the negotiations. While some tension existed in this regard during the BBNJ Working Group, it was noted that conditions have markedly improved as the process has moved forward, including in the ongoing BBNJ Preparatory Committee.

\section{Conclusion}

"I think you've always got the end goal, but you get kicked about by reality. As governments decide where they are going to go, you have to adapt." (NGO representative 3 )

The interviews suggest that the fostering of personal relations and the building of coalitions were among the most successful strategies for NGOs to contribute to the BBNJ Working Group process. However, the contribution of NGOs with regard to the provisioning of information through side events, publications, and expert input - met with a varied response from government delegations. While some governments welcomed these contributions, others felt that NGOs were disproportionately focused on conservation issues, in contrast with the General Assembly mandate to consider both conservation and sustainable use, and the entire package of issues.

At first glance, the key outcomes of the BBNJ Working Group may seem modest, namely the definition of a four-part package for further negotiation, and the formation of consensus to move ahead with such negotiations. Viewed within the context of the small handful of global instruments that have been adopted on ocean issues, however, the building of consensus on the need to move forward with negotiating an international legally binding instrument on BBNJ is quite a substantial step. Moreover, the process took on vast proportions, spanning a decade and including the participation of 1523 individuals representing governments and NGOs. The numbers grow even larger if one considers the additional officials and staff within governments and NGOs, who supported the efforts of these 1523 participants, but did not themselves attend the meetings. All the ripple effects of involving so many individuals around the world in this process will never be known, but can optimistically be pointed to as signifying growing levels of awareness and expertise with regard to ocean biodiversity issues.

The process has been marked from the beginning by NGO participation, and based on the reflections of individuals who were involved in the BBNJ Working Group, NGO participation has frequently been an asset to the process in a variety of ways. Despite the vast scale of the process, however, a recurring theme was the individual, and the key role of individuals (rather than governments or NGOs) in keeping the negotiations on track and moving forward in a mutually acceptable and constructive manner. The individuals and key players within the negotiation process have changed throughout the process, and further research could highlight how these dynamics continue to evolve. Collecting the perceptions of representatives from UNDOALOS and IGOs would fill a gap in this research area, and the role being played by the private sector intersessionally as well as on the sidelines of meetings remains unclear.

With the BBNJ Preparatory Committee, the process has now entered a new stage, yet the entry into force of an international legally binding instrument on BBNJ still seems a distant proposition. As noted in this paper, the continuity within delegations has been a hurdle throughout the process, and the first meetings of the BBNJ Preparatory Committee have also brought many new faces as well as the return of a few veterans who have been following the BBNJ process from the start. Full consensus has remained elusive on any of the package issues, as well as other fundamental questions regarding institutional arrangements and funding mechanisms for implementing a new agreement. The conventional wisdom according to several of the respondents interviewed for this study is that an international legally-binding instrument on BBNJ may still be a decade away. But as one government official noted: "[this] is the most important - and with the biggest implications - Law of the Sea issue since the negotiation of UNCLOS."

\section{Acknowledgement}

The authors would like to express their deep appreciation to all of the interview respondents who made this research possible by sharing their time and reflections on the BBNJ Working Group process. Advice and guidance by Henrik Österblom, Sebastian Unger and other colleagues was very valuable in shaping this research. We are also grateful for the particularly swift and constructive peer review process. This research was supported, in part, by Japan Society for the Promotion of Science KAKENHI grants (projects 24121010 and 16K18743).

\section{Appendix A. Supporting information}

Supplementary data associated with this article can be found in the online version at doi:10.1016/j.marpol.2017.03.004.

\section{References}

[1] S. Andresen, T. Skodvin, M.M. Betsill, E. Corell (Eds.), Non-state influence in the International Whaling Commission, 1970 to 2006, MIT Press, Cambridge, Massachusetts, 2008, pp. 19-42(244 pp).

[2] J.A. Ardron, R. Rayfuse, K. Gjerde, R. Warner, The sustainable use and conservation of biodiversity in ABNJ: What can be achieved using existing international agreements? Mar. Policy 49 (2014) 98-108.

[3] E. Becker, The influence of environmental NGOs in the global society, Butl. J. Undergrad. Res. 2 (2016) (Article 17).

[4] M.M. Betsill, E. Corell (Eds.), NGO Diplomacy: The influence of nongovernmental organizations in international environmental negotiations, MIT Press, Cambridge, Massachusetts, 2008 (244 pp).

[5] F. Biermann, P.H. Pattberg (Eds.), Global environmental governance reconsidered, MIT Press, Cambridge, 2012.

[6] R. Blasiak, N. Yagi, Shaping an international agreement on marine biodiversity beyond areas of national jurisdiction: lessons from high seas fisheries, Mar. Policy 71 (2016) 210-216.

[7] R. Blasiak, J. Pittman, N. Yagi, H. Sugino, Negotiating the use of biodiversity in marine areas beyond national jurisdiction, Front. Mar. Sci. (2016), http://dx.doi. org/10.3389/fmars.2016.00224.

[8] T. Böhmelt, C. Betzold, The impact of environmental interest groups in international negotiations: Do ENGOs induce stronger environmental commitments? Int. Environ. Agreem. 13 (2013) 127-151.

[9] H. Caminos, M.R. Molitor, Progressive development of international law and the package deal, Am. J. Int. Law 79 (4) (1985) 871-890.

[10] E. Corell, M.M. Betsill, Analytical framework: assessing the influence of NGO diplomats, in: M.M. Betsill, E Corell (Eds.), NGO diplomacy: The influence of nongovernmental organizations in international environmental negotiations, MIT Press, Cambridge, Massachusetts, 2008, pp. 19-42(244 pp).

[11] F. Dodds, Foreword, in: M.M. Betsill, E. Corell (Eds.), NGO Diplomacy: The influence of nongovernmental organizations in environmental negotiations, MIT Press, Cambridge, Massachusetts, 2008, pp. 1-18(244 pp).

[12] E. Druel, K.M. Gjerde, Sustaining marine life beyond boundaries: options for an implementing agreement for marine biodiversity beyond national jurisdiction under the United Nations Convention on the Law of the Sea, Mar. Policy 49 (2014) 90-97.

[13] E. Druel, J. Rochette, R. Bille, C. Chiarolla, The long and winding road. International discussions on the governance of marine biodiversity in areas beyond national jurisdiction, Studies Nr. 07/13, IDDRI, Paris, France, 42 p, 2012.

[14] M. Duwe, The climate action network: Global civil society at work? Reciel 10 (2) (2001) 1-14.

[15] Lars H. Gulbrandsen, Stein Andresen, NGO Influence in the Implementation of the Kyoto Protocol: Compliance, Flexibility Mechanisms, and Sinks, Glob. Environ. Polit. 4 (4) (2004) 54-75.

[16] M. Hanegraaf, J. Beyers, C. Braun, Open the door to more of the same: the development of interest group representation at the WTO, World Trade Rev. (2011), http://dx.doi.org/10.1017/S1474745611000310.

[17] J. Hewitt, Ethical components of research-researched relationships in qualitative interviewing, Qual. Health Res. 17 (8) (2007) 1149-1159.

[18] K. Houghton, J. Rochette, Introduction: advancing governance of areas beyond national jurisdiction, Marine Policy 49 (2014), pp. 81-84.

[19] D. Humphreys, Forest politics: the evolution of international cooperation, Earthscan, London, UK, 1996, p. 299.

[20] N. Kanie, F. Biermann (Eds.), Governing through goals: Sustainable development goals as governance innovation, MIT Press, Boston, USA, 2017, p. 352.

[21] M.E. Keck, K. Sikkink, Activists beyond borders: advocacy networks in international politics, Cornell University Press, Ithaca, NY, 1998, p. 228.

[22] C. Kőrösi, Negotiating a Common Future. What We Have Learned from the SDGs, in: 
R. Pachauri, A. Paugam, T. Ribera, L. Tubiana (Eds.), A Planet For Life. Building The Future We Want, TERI, Delhi, 2015, pp. 74-78(336 pp).

[23] A. Merrie, D.C. Dunn, M. Metian, A.M. Boustany, Y. Takei, A.O. Elferink, Y. Ota, et al., An ocean of surprises - Trends in human use, unexpected dynamics and governance challenges in areas beyond national jurisdiction, Glob. Environ. Change 27 (2014) 19-31.

[24] E. Morgera, Do we need a new treaty to protect biodiversity in the deep seas? IISD Reporting Series Policy Update No. 8, 2015, 2015.

[25] N. Nasiritousi, M. Hjerpe, B.O. Linnér, The roles of non-state actors in climate change governance: Understanding agency through governance profiles, Int. Environ. Agreem. 16 (2016) 109-126.

[26] P.J. Nelson, The World Bank and non-governmental organizations: the limits of apolitical development, Macmillan Press, New York, USA, 1995, p. 235.

[27] Y.I. Nicholls, Source Book: Emergence of Proposals for Recompensing Developing Countries for Maintaining Environmental Quality. IUCN Environmental Policy and Law Paper No. 5. Morges, Switzerland. 143 pp, 1973.

[28] R. Price, Reversing the gun sights: Transnational civil society targets land mines, Int. Organ. 52 (3) (1998) 613-644.

[29] K. Rietig, 'Neutral' experts? How input of scientific expertise matters in international environmental negotiations, Policy Sci. 47 (2014) 141-160.

[30] R. Scupin, The KJ method: a technique for Analyzing data derived from Japanese Ethnology, Hum. Organ. 56 (2) (1997) 233-237.

[31] J. Szarka, From climate advocacy to public engagement: an exploration of the roles of environmental non-governmental organisations, Climate 1 (2013) 12-27.
[32] J. Tallberg, L.M. Dellmuth, H. Agné, A. Duit, NGO Influence in International Organizations: Information, Access and Exchange, Br. J. Political Sci. (2015), http://dx.doi.org/10.1017/S000712341500037X.

[33] United Nations, Charter of the United Nations, 24 October 1945, 1 UNTS XVI (Retrieved on 25 October 2016 at: 〈http://www.refworld.org/docid/3ae6b3930. html)>, 1945.

[34] United Nations Convention on the Law of the Sea (UNCLOS), Montego Bay, 10 December 1982 (entered into force 16 November 1994), 1833 United Nations Treaty Series (UNTS) 3, 1982, 1982.

[35] United Nations General Assembly (UNGA) (2015) Letter dated 13 February, from the Co-Chairs of the Ad Hoc Open-ended Informal Working Group to the President of the General Assembly A/69/780. United Nations, New York, 2015.

[36] United Nations General Assembly (UNGA), Letter dated 30 June 2011 from the CoChairs of the Ad Hoc Open-ended Informal Working Group to the President of the General Assembly A/66/119. United Nations, New York, 2011.

[37] P. Willetts, Growth Number NGOs Consult. Status Econ. Soc. Counc. U. Nations (2015) (Retrieved on 24 October 2016 at), 〈http://www.staff.city.ac.uk/p.willetts/ NGOS/NGO-GRPH.HTM) $>$.

[38] G. Wright, J. Rochette, L. Blom, D. Currie, C. Durussel, K. Gjerde, S. Unger, High seas fisheries: what role for a new international instrument? (Study Nr. 03/2016) IDDRI, Paris, France, 2016, p. 20.

[39] G. Wright, J. Rochette, E. Druel, K. Gjerde, The long and winding road continues: towards a new agreement on high seas governance (IDDRI Study Nr. 01/2016), IDDRI, Paris, France, 2016, p. 49. 